\title{
Catalyst-Free Growth of Graphene by Microwave Surface Wave Plasma Chemical Vapor Deposition at Low Temperature
}

\author{
Sudip Adhikari*, Hare Ram Aryal, Hideo Uchida, Masayoshi Umeno \\ Department of Electronics and Information Engineering, Chubu University, Kasugai, Japan \\ Email: ${ }^{*}$ sudip@isc.chubu.ac.jp
}

Received 20 January 2016; accepted 19 March 2016; published 22 March 2016

Copyright (C) 2016 by authors and Scientific Research Publishing Inc.

This work is licensed under the Creative Commons Attribution International License (CC BY). http://creativecommons.org/licenses/by/4.0/

cC) (i) Open Access

\begin{abstract}
Catalyst-free graphene films has been synthesized by microwave (MW) surface wave plasma (SWP) chemical vapor deposition (CVD) using hydrogenated carbon source on silicon substrates at low temperature $\left(500^{\circ} \mathrm{C}\right)$. The synthesized process is simple, low-cost and possible for application on transparent electrodes, gas sensors and thin film resistors. Analytical methods such as Raman spectroscopy, transmission electron microscopy (TEM) and four points prove resistivity measurement and UV-VIS-NIR spectroscopy were employed to characterize properties of the graphene films. The formation of multilayer of graphene on silicon substrate was confirmed by Raman spectroscopy and TEM. It is possible to grow graphene directly on silicon substrate (without using catalyst) due to high radical density of MW SWP CVD. In addition, we also observed that the hydrogen had significant role for quality of graphene.
\end{abstract}

\section{Keywords}

Graphene Films, Direct Synthesis, $\mathrm{H}_{2}$ Flow Rate, Silicon Substrate, Microwave Surface Wave Plasma CVD

\section{Introduction}

Graphene is a single layer of $\mathrm{sp}^{2}$ hybridized carbon atoms arranged in a honeycomb lattice with hexagonal rings. Since the discovery of mono and few layers of graphene film (2004), it has become the attractive research subject in nanomaterial science due to its many unique physical, Chemical, mechanical properties and a possible use of low-cost flexible transparent electrodes, Photovoltaics or microelectronics devices [1]-[12]. However, to

*Corresponding author.

How to cite this paper: Adhikari, S., Aryal, H.R., Uchida, H. and Umeno, M. (2016) Catalyst-Free Growth of Graphene by Microwave Surface Wave Plasma Chemical Vapor Deposition at Low Temperature. Journal of Materials Science and Chemical Engineering, 4, 10-14. http://dx.doi.org/10.4236/msce.2016.43002 
obtain quality of graphene films, low-cost deposition method is still a significant challenge; a simple process of graphene synthesis is highly desirable, due to the fact that the method of synthesis of graphene has been focus of research in recent years [13] [14]. Several methods are used for growing graphene on various substrate, like; thermal chemical vapour deposition (CVD), micromechanical cleavage or chemical exfoliation of graphite, thermal decomposition of SiC on copper and nickel substrates [15] [16]. Among the various methods, thermal CVD has been a main method to synthesize of graphene, however it requires high temperature (above $\sim 1000^{\circ} \mathrm{C}$ ), catalyst films, post-transfer and additional catalyst removal process are needed. Direct growth of graphene without using any other catalyst and low growth temperature are very attractive.

In this work, we report the catalyst-free graphene synthesized on silicon substrate by microwave (MW) surface wave plasma (SWP) CVD using hydrocarbon as a plasma source gas at low temperature $\left(500^{\circ} \mathrm{C}\right)$. In addition, we compared the quality of graphene film grown on silicon substrate with different hydrogen $\left(\mathrm{H}_{2}\right)$ flow rate during deposition.

\section{Experimental Details}

Graphene film was synthesized by microwave (MW) surface wave plasma (SWP) chemical vapor deposition (CVD) on silicon substrate directly. Figure 1 shows schematic diagram of the CVD system. In this system, MW power, gas flow rate and deposition time-duration are controlled by touch-screen computer system. Because of the relatively large stage diameter $(20 \mathrm{~cm})$ of the CVD, it is possible to deposit a relatively large area graphene thin film or make simultaneous film deposition on various substrates in one experiment. The maximum MW power of the CVD system is $3 \mathrm{~kW}$, whereas the stage temperature can be controlled up to $700^{\circ} \mathrm{C}$. The MW-SWP is produce in a $300 \mathrm{~mm}$ cylindrical vacuum chamber by introducing a $2.45 \mathrm{GHz} \mathrm{MW}$ through a quartz window via slot antennae. The MW introduced through the slot antennae drops exponentially below the quartz window where the electron density exceeds the cut off density. A high plasma density with a uniform electron density of more than $10^{11} \mathrm{~cm}^{-3}$ is formed in the vacuum chamber and broadened in the downstream region due to particles diffusion. Unlike other plasma sources the SWP is a promising plasma source for large-area thin film deposition and useful to avoid plasma induced damages of the substrates surfaces [17]. Argon (Ar: $100 \mathrm{sccm}$ ), Hydrogen $(\mathrm{H}=0-35 \mathrm{sccm})$ and acetylene $\left(\mathrm{C}_{2} \mathrm{H}_{2}: 5 \mathrm{sccm}\right)$ were used for plasma source. The detail substrate cleaning process is described elsewhere [18]. The MW SWP CVD chamber was evacuated to a base pressure at approximately $5 \times 10^{-4} \mathrm{~Pa}$ using a turbo pumps. The launched microwave power was typically $1300 \mathrm{~W}$ and a constant

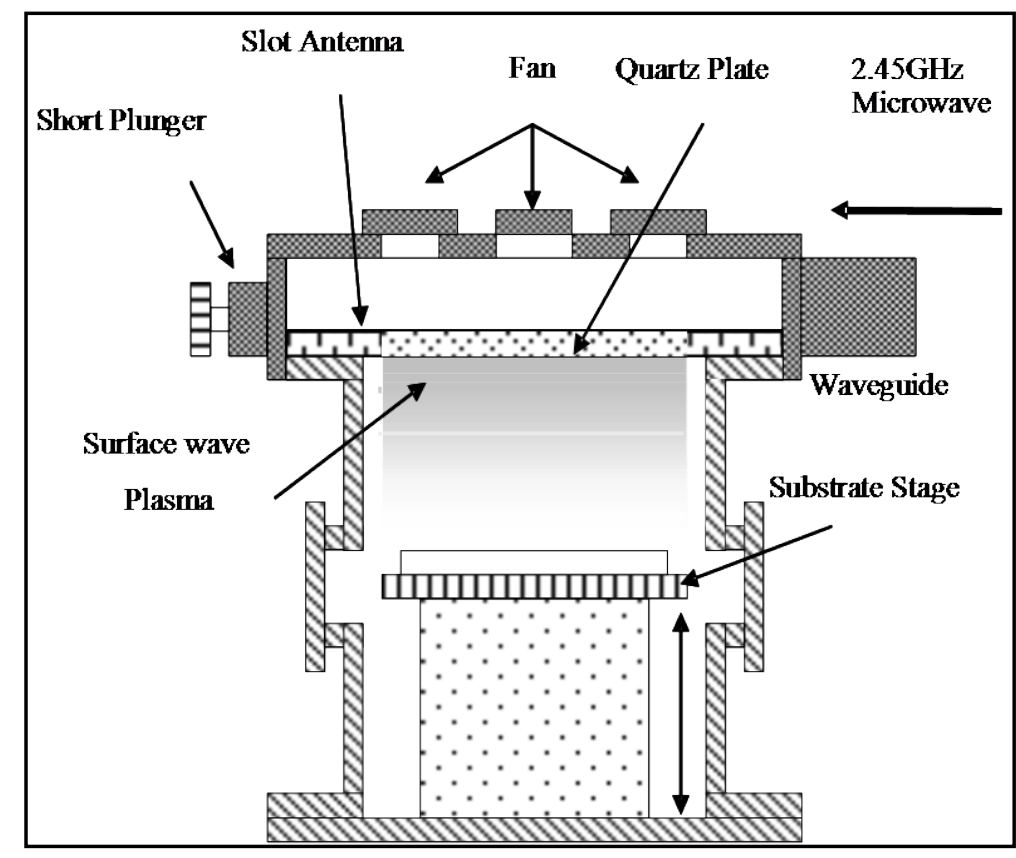

Figure 1. Schematic diagram of the MW SWP CVD system. 
gas composition pressure is maintained at $20 \mathrm{~Pa}$ and substrate temperature was $500^{\circ} \mathrm{C}$ during deposition. The duration of films deposition was $4 \mathrm{~min}$. The synthesized graphene were characterized, by Raman spectroscopy, Transmission electron microscopy (TEM), four point probe method for resistivity measurement and UV-VISNIR spectroscopy.

\section{Results and Discussion}

Figure 2 shows the Raman spectra (a), ration of $\mathrm{I}_{d} / \mathrm{I}_{\mathrm{g}}$ (b), full with half maximum (FWHM) of 2D peaks (c) and sheet resistivity of graphene films with different $\mathrm{H}_{2}$ flow rate (0 to $35 \mathrm{sccm}$ ) during deposition. It shows (Figure 2(a)) that all spectra have three peaks centered at 1346, 1576 and $2691 \mathrm{~cm}^{-1}$ which is assigned to the D (disorder mode), G (graphite mode) and 2D (D mode overtone) modes of graphene respectively. It is reported that the D-peak represents disorder $\mathrm{sp}^{2}$-hybridized carbon with an amount of $\mathrm{sp}^{3}$-hybrodized carbon, while the G-peak represents graphite-like $\mathrm{sp}^{2}$-hybridized carbon in deposited film [19]. The presence of 2D peak shows a good agreement of graphene structure formation into the film. The Raman spectrum of carbon material is quite remarkable in order to study the quality of graphene structure [20].

The spectra (Figure 2(b)) shows $\mathrm{I}_{\mathrm{d}} / \mathrm{Ig}$ decreased with increasing hydrogen flow rate up to 25 sccm. Then, it started to increase with increasing hydrogen flow rate $(35 \mathrm{sccm})$. The results show that the defect of graphene films has gradually decreasing with increasing hydrogen flow rate from 0 to 25 sccm due to the formation of C-H bonds.

The full with half maximum (FWHM) of 2D peak decreased with increasing $\mathrm{H}_{2}$ flow rate, seen in Figure 2(c). The results show that the crystalline quality of graphene improving with increasing hydrogen flow rate. It is reported that hydrogen can control the grains shape and dimension by etching away the weak carbon-carbon (C-C) bonds and it can contribute to improve the graphene layer uniformly [21].

We found that the quality of graphene improved with increasing hydrogen concentration into the film, at the same time we also observed that the sheet resistant increased with increasing hydrogen flow rate, as can be seen in Figure 2(d). As graphene reacts with hydrogen atoms forming $\mathrm{C}-\mathrm{H}$ bonds on the basal plane of graphene the resistivity of the film is increased [22].

The structural morphology of the graphene film (hydrogen flow rate $25 \mathrm{sccm}$ ) was characterized by transmission electron microscopy (TEM). The TEM characterization shows in Figure 3 (low resolution (a) and high resolution (b)), reveal the graphene layers and crystalline information of the graphene film synthesized on silicon substrate. As observed that the synthesized graphene is multilayered ( $\approx 4$ layers) shows in intensity pattern (up inset of Figure 3(b)); an inter-planar spacing of about $0.35 \mathrm{~nm}$ and the fast fourier transform (FFT) image (below inset of Figure 3(b)) shows a graphite crystalline structure (hexagonal atomic arrangement).
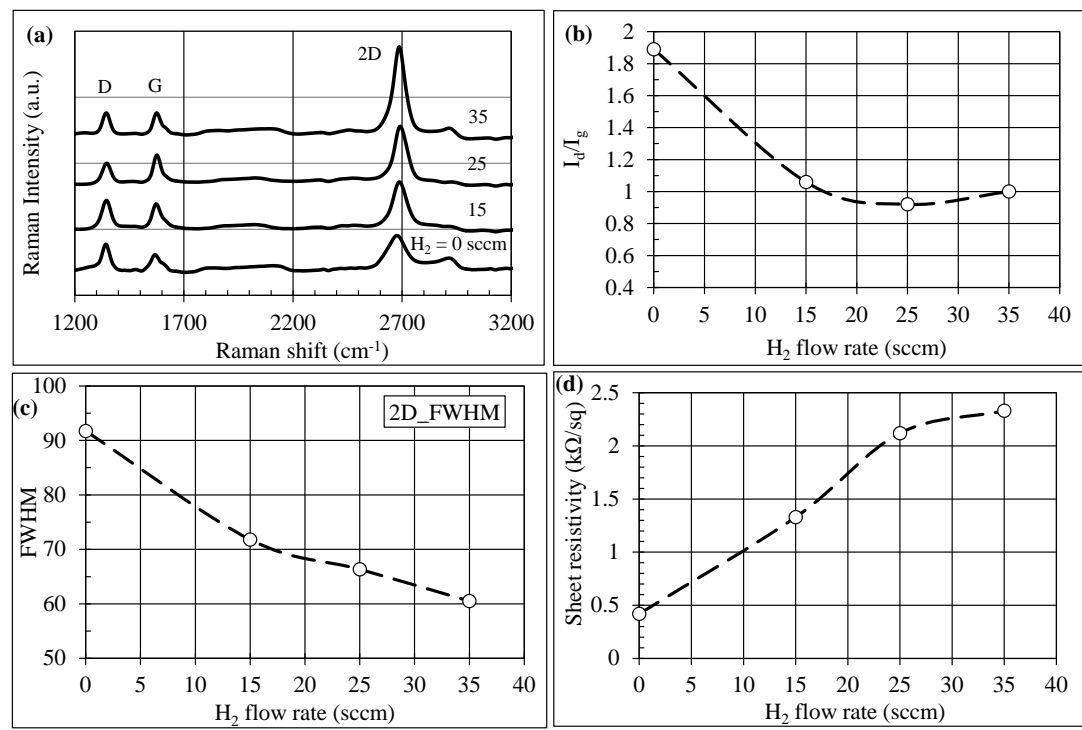

Figure 2. Raman spectra (a); ration of $\mathrm{I}_{d} / \mathrm{I}_{\mathrm{g}}$ (b); full with half maximum (FWHM) of 2D peaks (c) and sheet resistivity of graphene films with different $\mathrm{H}_{2}$ flow rate (0 to $35 \mathrm{sccm}$ ). 


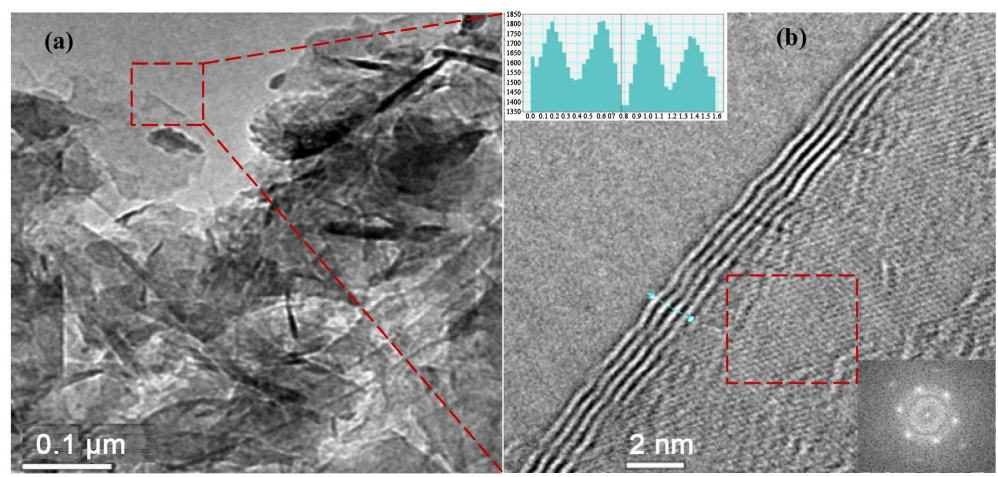

Figure 3. Transmission electron microscopy (TEM); low resolution (a) and high resolution (HR) (b) image of the graphene film deposited on silicon substrate (hydrogen flow rate 25 $\mathrm{sccm}$ ). In the inset (up left side), the intensity pattern of the graphene multilayers ( $\approx 4$ layers) is presented. In the inset (down right side), a fast fourier transform (FFT) image of the film, showing a set of hexagonal sports in the different pattern.

\section{Conclusion}

We have developed graphene film directly on silicon substrate by microwave (MW) surface wave plasma (SWP) chemical vapor deposition (CVD) at low temperature $\left(500^{\circ} \mathrm{C}\right)$ using hydrocarbon as a source gas. Direct synthesis of graphene (without using catalyst) on silicon substrate is possible due to high radical density of MW SWP CVD. In addition, we synthesized four different graphene films on silicon substrate directly with increasing hydrogen flow rate (0 to $35 \mathrm{sccm}$ ) during deposition. The results showed that the hydrogen had significant role for improving quality of graphene because hydrogen can control the grains shape and dimension by etching away the weak carbon-carbon (amorphous and other oxidized carbon) bonds.

\section{Acknowledgements}

We would like to express sincere thanks to Mr. kawamura for his help during TEM measurement.

\section{References}

[1] Novoselov, K.S., Geim, A.K., Morozov, S.V., Jiang, D., Zhang, Y., Dubonos, S.V., Grigorieva, I.V. and Firsov A.A. (2004) Electric Field Effect in Atomically thin Carbon Films. Science, 306, 666-669. http://dx.doi.org/10.1126/science.1102896

[2] Yan, J., Zhang, Y., Goler, S., Kim, P. and Pinczuk, A. (2007) Raman Scattering and Tunable Electron-Phonon Coupling in Single Layer Graphene. Solid State Communications, 143, 39-43. http://dx.doi.org/10.1016/j.ssc.2007.04.022

[3] Mkhoyan, K.A., Contryman, A.W., Silcox, J., Stewart, D.A., Eda, G., Mattevi, C., Miller, S. and Chhowalla, M. (2009) Atomic and Electronic Structure of Graphene-Oxide. Nano Letters, 9, 1058-1063. http://dx.doi.org/10.1021/nl8034256

[4] Lee, C., Wei, X., Kysar, J.W. and Hone, J. (2008) Measurement of the Elastic Properties and Intrinsic Strength of Monolayer Graphene, Science, 321, 385-388. http://dx.doi.org/10.1126/science.1157996

[5] Orlita, M., Faugeras, C., Plochocka, P., Neugebauer, P., Martinez, G., Maude, D.K., Barra, A.-L., Sprinkle, M., Berger, C. and de Heer, W.A. (2008) Approaching the Dirac Point in High-Mobility Multilayer Epitaxial Graphene. Physical Review Letters, 101, 267601. http://dx.doi.org/10.1103/physrevlett.101.267601

[6] Ishigami, M., Chen, J.H., Cullen, W.G., Fuhrer, M.S. and Williams, E.D. (2007) Atomic Structure of Graphene on $\mathrm{SiO}_{2}$. Nano Letters, 7, 1643-1648. http://dx.doi.org/10.1021/nl070613a

[7] Blake, P., Brimicombe, P.D., Nair, R.R., Booth, T.J., Jiang, D., Schedin, F., Ponomarenko, L.A., Morozov, S.V., Gleeson, H.F. and Hill, E.W. (2008) Graphene-Based Liquid Crystal Device. Nano Letters, 8, 1704-1708. http://dx.doi.org/10.1021/nl080649i

[8] Geim, A.K. and Novoselov, K.S. (2007) The Rise of Graphene. Nature Materials, 6, 183-191. http://dx.doi.org/10.1038/nmat1849

[9] Wang, X., Zhi, L. and Müllen, K. (2008) Transparent, Conductive Graphene Electrodes for Dye-Sensitized Solar Cells. Nano Letters, 8, 323-327. http://dx.doi.org/10.1021/nl072838r

[10] Meyer, J.C., Geim, A.K., Katsnelson, M.I., Novoselov, K.S., Booth, T.J. and Roth, S. (2007) The Structure of Sus- 
pended Graphene Sheets. Nature, 446, 60-63. http://dx.doi.org/10.1038/nature05545

[11] Lin, Y.-M., Jenkins, K.A., Valdes-Garcia, A., Small, J.P., Farmer, D.B. and Avouris, P. (2009) Operation of Graphene transistors at Gigahertz Frequencies. Nano Letters, 9, 422-426. http://dx.doi.org/10.1021/nl803316h

[12] Lee, H.-J., Kim, E., Yook, J.-G. and Jung, J. (2012) Intrinsic Characteristics of Transmission Line of Graphenes at Microwave Frequencies. Applied Physics Letters, 100, 223102-223103. http://dx.doi.org/10.1063/1.4722585

[13] Wei, D. and Xu, X. (2012) Laser Direct Growth of Graphene on Silicon Substrate. Applied Physics Letters, 100, Article ID: 023110. http://dx.doi.org/10.1063/1.3675636

[14] Choi, W., Lahiri, I., Seelaboyina, R. and Kang, Y.S. (2010) Synthesis of Graphene and Its Applications: A Review. Critical Reviews in Solid State and Materials Sciences, 35, 52. http://dx.doi.org/10.1080/10408430903505036

[15] Somani, P.R., Somani, S.P. and Umeno, M. (2006) Planer Nano-Graphenes from Camphor by CVD. Chemical Physics Letters, 430, 56-59. http://dx.doi.org/10.1016/j.cplett.2006.06.081

[16] Dato, A., Radmilovic, V., Lee, Z., Phillips, J. and Frenklach, M. (2008) Substrate-Free Gas-Phase Synthesis of Graphene Sheets. Nano Letters, 8, 2012-6. http://dx.doi.org/10.1021/nl8011566

[17] Umeno, M. and Adhikary, S. (2005) Diamond-Like Carbon Thin Films by Microwave Surface-Wave Plasma CVD Aimed for the Application of Photovoltaic Solar Cells. Diamond and Related Materials, 14, 1973-1979. http://dx.doi.org/10.1016/j.diamond.2005.09.030

[18] Adhikari, S., Omer, A.M.M., Adhikary, S., Rusop, M., Uchida, H. and Umeno, M. (2006) Diamond-Like Carbon Thin Films Grown by Large-Area Surface-Wave Mode Microwave Plasma CVD: Effects of Stage Distance to Microwave Window. Diamond and Related Materials, 15, 913-916. http://dx.doi.org/10.1016/j.diamond.2005.12.012

[19] Dillon, R.O., Woollam, J.A. and Katkanant, V. (1984) Use of Raman Scattering to Investigate Disorder and Crystallite Formation in As-Deposited and Annealed Carbon Films. Physical Review B, 29, 3482-3489. http://dx.doi.org/10.1103/PhysRevB.29.3482

[20] Ferrari, A.C., Meyer, J.C., Scardaci, V., Casiraghi, C., Lazzeri, M., Mauri, F., Piscanec, S., Jiang, D., Novoselov, K.S., Roth, S. and Geim, A.K. (2006) Raman Spectrum of Graphene and Graphene Layers. Physical Review Letters, 97, Article ID: 187401. http://dx.doi.org/10.1103/PhysRevLett.97.187401

[21] Losurdo, M., Giangregorio, M.M., Capezzuto, P. and Bruno, G. (2011) Graphene CVD Growth on Copper and Nickel: Role of Hydrogen in Kinetics and Structure. Physical Chemistry Chemical Physics, 13, 20836-20843. http://dx.doi.org/10.1039/c1cp22347j

[22] Duplock, E.J., Scheffler, M. and Lindan, P.J.D. (2004) Hallmark of Perfect Graphene. Physical Review Letters, 92, Article ID: 225502. http://dx.doi.org/10.1103/PhysRevLett.92.225502 